\title{
Hepatitis C Virus: From Liver to Bone Disease, There are Multiple Stations
}

\author{
Mohamed I Radwan and Ehab M Darweish \\ Tropical Medicine Department, Faculty of Medicine, Zagazig University, Egypt \\ See the full article pages
}

\section{Background}

Osteoporosis is defined as a "progressive systemic skeletal disease characterized by low bone mass and microarchitectural deterioration of bone tissue, with a consequent increase in bone fragility and susceptibility to fracture" Common fractures are vertebral compression fractures, fractures of the distal radius, and proximal femur [1].

World Health Organization defines osteoporosis as a bone mineral density (BMD) measurement of 2.5 standard deviations or more below the population mean BMD of sex-matched young adults, i.e., a t-score of $\leq-2.5$. The term "established osteoporosis" includes the presence of a fragility fracture [2].

Osteoporosis can result in spontaneous or low trauma fractures in the patients, adversely affecting morbidity, quality of life. The prevalence of osteoporosis associated fracture ranges from $5 \%$ to $20 \%$ [3].

\section{Hepatic Osteodystrophy}

Osteoporosis and osteopenia are well known complications in patients with chronic liver disease. Its prevalence varies considerably. It ranges from 12 to $55 \%$ according to many factors including patient selection, diagnostic criteria, underlying liver disease [4] and it also increases with the increased severity of the liver disease defined as advanced Child-Pugh score [5].

Osteoporosis is a risk factor for development of fractures, which may be a source of morbidity in patients already debilitated by chronic liver disease. Prevention of morbidity of hepatic osteodystrophy is to identify those patients who are predisposed to development of osteopenia and osteoporosis [5].

Hepatic bone disease is caused by a variety of causes ranging from chronic hepatitis as $\mathrm{HCV}$ and HBV [6] to cirrhosis. Compensated as well as decompensated cirrhosis whatever its cause affect BMD leading to osteopenia and osteoporosis [7]. Patients awaiting for liver transplantation have different degree of osteopenia as well as osteoporosis [8]. Osteoporosis and osteopenia are alterations in BMD that frequently occur in chronic liver disease; predominantly in chronic cholestatic disease and liver cirrhosis [9].

\section{Hepatitis C Virus and Bone affection}

Chronic hepatitis $\mathrm{C}(\mathrm{HCV})$ is systemic disease rather than hepatotropic virus. HCV affects more than 170 million people worldwide [10] and is the single important cause of liver disease in Egypt [11]. It is associated with multisystemic manifestations [12]. Liver disease is the most common affectation, and leads to liver cirrhosis and hepatocellular carcinoma [13].

Osteopenia and osteoporosis are common in chronic HCV patients. In most studies suggesting that HCV by itself provokes osteopenia [14]. Some of this research involved non cirrhotic patients [14], others, individuals affected by liver cirrhosis [15], or both cirrhotics and non-cirrhotics [16], and some were restricted to patients awaiting organ transplantation [17] and also in renal transplant patients infected with HCV [18].

The pathogenesis of osteoporosis in chronic liver disease including HCV is still unknown and it is most likely that multiple factors are operating simultaneously [19].

The development of osteoporosis may be related to both increase bone resorption and/ or decrease bone formation [20]. Inhibition of osteoblast (bone forming cell) by retained substances of cholestasis as unconjugated bilirubin, retained bile acids, toxic effect of alcohol, and excessive tissue iron deposition [21].

Various potential inciting factors that either directly or indirectly alter bone mass are insulin- 
like growth factor 1 (IGF-1) deficiency, hyperbilirubinemia, hypogonadism, subnormal 25-hydroxyvitamin D levels, vitamin D receptor genotypes, vitamin $\mathrm{K}$, osteoprotegerin (OPG) and receptor activator of nuclear factor interactions and concurrent use of drugs like cholestyramine, diuretics, glucocorticoids and immunosuppressive agents [6-22]. Lifestyle factors (smoking, alcoholism, and immobility), malnutrition and low body mass index [23].

Increase osteoclast activity is cytokine mediated mechanism of bone loss. The proinflammatory cytokines interleukin-1(IL-1) and tumor necrosis factor (TNF) increase osteoclast activity and are increased in hepatic inflammation and fibrosis. TNF increased in viral hepatitis and alcoholic liver disease as well as in patients with cirrhosis [24].

Application of therapy must consider general measures (correction of reversible risk factors, calcium intake and supplementation) and specific treatment for osteoporosis. Bisphosphonates are antiresorptive drugs that can improve BMD in other chronic liver disease, but only limited data are available for osteoporosis in $\mathrm{HCV}$ infection [6].

\section{Summary and Comment on the paper}

In this issue of the Afro-Egyptian Journal of Infectious and Endemic Diseases Abdelkader et al. [25], discussed the impact of HCV on BMD both in cases with chronic hepatitis and in cases with HCV cirrhosis in comparison to apparently healthy controls. The authors included 80 participants. Of them 30 patients were chronic HCV infection without cirrhosis, 30 patients were chronic HCV infection with compensated cirrhosis and 20 age and gender matched apparently healthy controls. All subjects of the study performed liver function tests, viral markers, liver biopsy, hormonal assay and BMD measurement by Dual energy X-ray absorptiometry (DEXA). They found that in patients with chronic hepatitis $\mathrm{C}$ the frequency of osteopenia was $36.7 \%$, osteoporosis was $6.7 \%$, total patients with low BMD were $43.3 \%$. In cirrhotic patients, the frequency increased as follow: osteopenia was $43.3 \%$, osteoporosis was $10.0 \%$, and total patients with low BMD were $53.3 \%$ vs $5.0 \%$ in the healthy controls. There was also no significant difference between patients with low BMD and patients with normal $\mathrm{BMD}$ as regards age, gender, common risk factors, liver function tests or hormonal levels. They concluded that reduced BMD is common in chronic HCV-infected patients and consequently, $\mathrm{HCV}$ infection is a risk factor of osteoporosis, and this risk is increased with advancement of the liver disease.

The paper looks interesting because it discuss an important issue that we commonly face in the everyday clinical practice. Liver cirrhosis is a debilitating condition and with increase in the severity it seems that BMD affection increases and more morbidity awaits the patients. We suppose that this study do have some limitations, the first of all is the small sample size. A large sample may be more presentable to the level which present of this big problem. Second, the cross sectional design of this study, a prospective study is more valuable and may address the $\mathrm{HCV}$ induced BMD morbidities more clearly. Third, exclusion criteria needs to be more dependable and should include for example smokers, alcohol abusers, patients under hormonal therapy affecting calcium metabolism, patients with thyroid and parathyroid disturbances, severe renal insult and associated HBV infection. Lastly, a selection bias seems to be present. It not obvious how patients were selected and how they were randomized.

\section{Recommendations:}

According to the previous discussion, it may be valuable to conduct a prospective study over a long period of time to evaluate the impact of $\mathrm{HCV}$ on the bone health. Implication of $\mathrm{HCV}$ genotyping during this study may add to our knowledge is there any impact of HCV genotype on BMD?. Likewise, little is known about the effect of antiviral agents against HCV on BMD and their potential benefit on bone impairment. Hence, impact of HCV therapy on the HCV induced $\mathrm{BMD}$ affection needs further investigation.

\section{References}

1. Rachner T, Khosla S, Hofbauer L. Osteoporosis: now and the future. The Lancet. 2001; 377(9773): 1276-1287.

2. World Health Organization Study Group. Assessment of fracture risk and its application to screening for postmenopausal osteoporosis. World Health Organ Tech Rep Ser. 1994; 843:1-129.

3. Raisz L. Pathogenesis of osteoporosis: concepts, conflicts, and prospects. J Clin Invest 2005; 115(12): 3318-3325. 
4. Lin J, Hsieh T, Wu C, Chen P, Chueh T, Chang $\mathrm{W}$, et al. Association between chronic hepatitis C virus infection and bone mineral density. Calcif Tissue Int. Dec 2012; 91(6):423-429.

5. López-Larramona G, Lucendo A, González-Castillo S, Tenias JM. Hepatic osteodystrophy: An important matter for consideration in chronic liver disease. World J Hepatol. 2011; 3(12):300-307.

6. Yurci A, Kalkan A, Ozbakir O, Karaman A, Torun E, Kula M, et al. Efficacy of different therapeutic regimens on hepatic osteodystrophy in chronic viral liver disease. Eur J Gastroenterol Hepatol. 2011; 23(12):1206-12.

7. Orsini L, Pinheiro M, Castro C, Silva A, Szejnfeld V. Bone mineral density measurements, bone markers and serum vitamin D concentrations in men with chronic non-cirrhotic untreated hepatitis C. PLoS One. 2013; 8(11):e81652.

8. Alcalde Vargas A, Pascasio Acevedo J, Gutiérrez Domingo I, García Jiménez R, Sousa Martín J, Ferrer Ríos M, et al. Prevalence and characteristics of bone disease in cirrhotic patients under evaluation for liver transplantation. Transplant Proc. 2012; 44(6):1496-8.

9. López-Larramona G, Lucendo A, González-Delgado L. Alcoholic liver disease and changes in bone mineral density. Rev Esp Enferm Dig. 2014; 105(10):609-621.

10. Lavanchy D. Evolving epidemiology of hepatitis C virus. Clin Microbiol Infect 2011; 17(2):107115.

11. Habib M, Mohamed M, Abdel-Aziz F, Magder L, Abdel-Hamid M, Gamil F, et al. Hepatitis C virus infection in a community in the Nile Delta: risk factors for seropositivity. Hepatology 2001; 33(1): 248 .

12. Soliman A, El hawari SA, Refaey MM, Ahmed $\mathrm{NH}$, Emara MH. Extrahepatic Manifestations of Hepatitis C Virus: An Extending List.Afro-Egypt $J$ Infect Endem Dis 2012; 2(1): 36-53

13. Mueller S, Millonig G, Seitz H. Alcoholic liver disease and hepatitis C: a frequently underestimated combination. World J Gastroenterol.2009;15(28): 3462-71.

14. Schiefke I, Fach A, Wiedmann M, Aretin A, Schenker E, Borte G, et al. Reduced bone mineral density and altered bone turnover markers in patients with non cirrhotic chronic hepatitis B or C infection. World J Gastroenterol. 2005; 11(12): 1843-1847.

15. Carey E, Balan V, Kremers W, Hay J. Osteopenia and osteoporosis in patients with end-stage liver disease caused by hepatitis $\mathrm{C}$ and alcoholic liver disease: not just a cholestatic problem. Liver Transplant 2003; 9(11): 1166-1173.

16. Raslan H, Elhosary Y, Ezzat W, Rasheed E, Rasheed M. The potential role of insulin-like growth factor 1, insulin-like growth factor binding protein 3 and bone mineral density in patients with chronic hepatitis $\mathrm{C}$ virus in Cairo, Egypt. Trans R Soc Trop Med Hyg. 2011;104(6):429432.

17. Loria I, Albanese C, Giusto M, Galtieri P, Giannelli $\mathrm{V}$, Lucidi C, et al. Bone disordersin patients with chronic liver disease awaiting liver transplantation. Transplant Proc. 2010; 42(4): 1191-3.

18. Huang WH, Yu MC, Huang JY, Lai PC. Impact of Hepatitis C Virus Infection on Bone Mineral Density in Renal Transplant Recipients. PLoS ONE 2013; 8(5): e63263.

19. Wariaghli G, Allali F, El Maghraoui A, HajjajHassouni N. Osteoporosis in patients with primary biliary cirrhosis. Eur J Gastroenterol Hepatol. 2010; 22(12):1397-401.

20. Mualouf $\mathrm{N}$ and Sakhaee K. Treatment of Osteoporosis in Patients with Chronic Liver Disease and in Liver Transplant Recipients. Curr Treat Options Gastroenterol 2006; 9(6):456-463.

21. Guañabens N and Parés A. Management of osteoporosis in liver disease. Clin Res Hepatol Gastroenterol. 2011; 35(6-7):438-445.

22. Goel V and Kar P. Hepatic osteodystrophy. Trop Gastroenterol. 2010; 31(2):82-6.

23. Hay $\mathbf{J}$ and Guichelaar M. Evaluation and management of osteoporosis in liver disease. Clin Liver Dis. 2005;9(4): 747-766.

24. Luxon B. Bone disorders in chronic liver diseases. Curr Gastroenterol Rep. 2011; 13(1):40-48.

25. Abdelkader AH, Hegazy IM, Elbadrawy EG, Zeid AF, Shawky JA, El-Hawari SA, et al. Osteoporosis in chronic hepatitis C. Afro-Egypt $J$ Infect Endem Dis 2014; 4(3). 